\title{
A noção de equação e suas diferentes concepções: uma investigação baseada em aspectos históricos e epistemológicos
}

\author{
The notion of equation and its different conceptions: \\ an investigation based on \\ historical and epistemological aspects
}

Alessandro Jacques Ribeiro

\begin{abstract}
Resumo
O presente artigo tem por finalidade apresentar os caminhos traçados pelas equações ao longo da história da Matemática e seus reflexos no desenvolvimento da Matemática. A busca pela solução das equações algébricas foi durante muito tempo um desafio para o homem. Considerando os principais momentos em que a história das equações se emaranhava com a história da Matemática, este artigo pretende trazer contribuições para pesquisas relacionadas ao ensino e aprendizagem de Álgebra, assim para o processo de ensino e aprendizagem da Matemática em sala de aula, na medida em que é uma fonte de reflexão sobre a influência da epistemologia da ciência nos processos didáticos em nossa área de atuação..
\end{abstract}

Palavras-chave: Equação. História da Matemática. História das Equações. Desenvolvimento da Álgebra.

\begin{abstract}
The present article has the aim to present the ways traced by equations throughout the history of the Mathematics and its consequences in its development. The search for the solution of the algebraic equations has always been a challenge for man. Considering the main moments where the history of the equations became entangled with the history of the Mathematics, this article intends to contribute with researches in teaching and learning of Algebra, as well as teaching and learning of Mathematics in classroom, as it is a source to reflection on as how it gives an influence on the epistemology of science in the didactic processes in our area of performance.
\end{abstract}

Keywords: Equation. History of Mathematics. History of Equations. Algebra Development. 


\section{Introdução}

Este artigo é parte integrante de um trabalho mais amplo que busca identificar os significados para a noção de equação no ensino de Matemática. Apresento aqui um estudo bibliográfico, no qual analiso a trajetória epistemológico-histórica da noção de equação, identificando como diferentes povos, em diferentes épocas, concebiam a noção ao longo do desenvolvimento da História da Matemática. Os resultados dessa investigação contribuíram para a identificação de diferentes formas de se conceber a noção de equação no ensino de Matemática (RIBEIRO, 2007).

Partindo de pesquisas recentes como Kieran (1992), que levanta o fato de se trabalhar em demasia com o aspecto processual da Álgebra, Cotret (1997) em sua pesquisa sobre as dificuldades que surgem quando do equacionamento de problemas escritos e Ribeiro (2001), que identificou um resultado pouco expressivo quando alunos de 13-14 anos trabalharam com questões envolvendo equações, é possível constatar a ênfase que é dada aos procedimentos e técnicas de resolução, quando se está trabalhando com as equações.

Nesse sentido, minha preocupação em identificar e divulgar os diferentes significados que podem e, a longo prazo, devem ser atribuídos à noção de equação, reflete uma posição na qual não podemos conceber a noção de equação simplesmente como um conjunto de técnicas e procedimentos de resolução, ou focar nosso interesse somente nesse aspecto.

Entendendo o processo de significação como a construção de significado de objetos matemáticos por intermédio de uma relação pessoal, a principio, entre o individuo e o objeto matemático quando de sua utilização e manipulação, assim, recorro a Duval (1993) que discute a questão da compreensão em Matemática implicar na capacidade de articularmos diferentes registros de representação semiótica de um mesmo objeto matemático, articulação essa que é necessária, mas não é suficiente, para a constituição do conhecimento matemático.

Desse modo, este estudo epistemológico-histórico considera os diferentes registros de representação vinculados às diferentes formas com que a noção de equação foi sendo concebida ao longo da história.

O presente trabalho foi desenvolvido a partir de um estudo bibliográfico de diversos autores da área da História da Matemática. Inicio apresentando a Matemática dos Babilônios e Egípcios, dos Gregos. Trago em seguida as descobertas dos Árabes e Hindus, e, finalmente, as contribuições que os Europeus Renascentistas trouxeram para um dos maiores problemas que permearam a Matemática até o século XIX - a busca pela resolução das equações quínticas. 


\section{Babilônios e Egípcios}

Eves (2004) aponta para o fato de que uma marca bastante forte e presente na Matemática dos Babilônios refere-se a uma geometria de caráter puramente algébrico, com problemas expressos em terminologia geométrica, mas que não passam de problemas algébricos não triviais. Por volta do ano 2000 a.C. a aritmética babilônica parecia já ter evoluído para uma álgebra retórica desenvolvida. Eles resolviam equações lineares e quadráticas com duas incógnitas, tanto pelo método equivalente ao de substituição numa fórmula geral, como pelo método de completar quadrados.

A álgebra naquela época era utilizada para resolver problemas por meio de equações que ainda, nos dias de hoje, requerem uma considerável habilidade numérica, e nota-se ainda que os babilônios eram infatigáveis construtores de tábuas de cálculos, calculistas extremamente hábeis e certamente mais fortes em álgebra do que em geometria. (EVES, 2004, p. 63)

Juntamente com a Babilônia, destaco o Egito, berço de uma das mais antigas civilizações da humanidade. Dentre os documentos matemáticos mais antigos que chegaram aos dias atuais, talvez os mais famosos sejam os papiros egípcios. Os papiros de Rhind e de Moscou juntos contêm 110 problemas. A maioria dos problemas apresentados nos papiros era de origem prática, com questões sobre pão, cerveja, o balanceamento de rações para o gado e aves. Muitos desses problemas eram resolvidos por uma equação linear com uma incógnita, utilizando-se de um método que, mais tarde na Europa, ficou conhecido por regra da falsa posição.

Os problemas eram normalmente simples e não iam além das equações lineares com uma incógnita, a qual eles representavam por hau ou aha. Suas soluções não exigiam grandes métodos e raciocínios, sendo que o mais empregado, o da falsa posição, assemelha-se bastante com o que conhecemos hoje como "método das tentativas".

Em Dahan-Dalmenico \& Peiffer (1986) outro fato importante a se destacar é que, nos papiros encontrados, as resoluções de equação eram sempre seguidas de instruções do tipo "faça isto", "faça aquilo", "este é o resultado", sem qualquer tipo de justificativa lógica. A meu ver, podemos ainda reconhecer indícios dessa "concepção" nos dias atuais, quando se trata de uma perspectiva de ensino-aprendizagem baseada na manipulação de regras e algoritmos sem muita preocupação com a discussão dos significados das idéias matemáticas.

Baseado nessas características dos babilônios e egípcios pode-se concluir que nesse período trabalhava-se basicamente com equações originárias de problemas de ordem prática como aqueles ligados à agricultura e divisão de terras. A noção de equação utilizada por essas civilizações, principalmente pelos egípcios, tinha um caráter pragmático e procurava, de forma 
intuitiva, igualar duas quantidades, com a finalidade de encontrar o valor da quantidade desconhecida.

Percebe-se durante essa fase da história das equações, que, na maior parte das vezes, a busca pelas soluções relacionava-se a equações particulares, para resolver problemas específicos. Os métodos utilizados, em sua maior parte, estavam ligados a idéias aritméticas e não tinham como preocupação a busca por soluções gerais para esses tipos de equações.

\section{Gregos}

Considerando que este estudo delimita períodos históricos para sua investigação, isto acarreta que gregos apareçam em separado dos europeus renascentistas, justamente pelo fato destes últimos terem vivido em período histórico diferente dos primeiros.

Durante esse período surgiram relatos sobre um grande número de matemáticos preocupados com os problemas que trouxeram desenvolvimento para a geometria. Tratava-se do período da "Idade Heróica da Matemática" em que a álgebra aritmética era substituída por uma álgebra geométrica. Em sua álgebra geométrica, os gregos utilizavam dois métodos principais para a resolução de equações lineares e quadráticas - o método das proporções e o da aplicação de áreas, métodos esses que parecem ter suas origens nos pitagóricos.

Garbi (1997) no livro O Romance das Equações Algébricas apresenta o método das proporções utilizado pelos gregos, método esse que permite que se construa um segmento de reta $x$, dado por $a: b=c: x$ ou por $a: x=x: b$, em que $a, b, c$ são segmentos de reta dados. Esse método fornece soluções geométricas para equações do tipo $a x=b c$ e $x^{2}=a b$.

Os gregos normalmente distinguiam grandezas de dimensões diferentes - uma, duas ou três. Suas discussões giravam em torno de situações em que surgia a necessidade de se adicionar tais grandezas, pois isso somente poderia ocorrer entre grandezas de mesma dimensão. Tais discussões demandavam de problemas originados da pergunta: Como encontrar o segmento $x$ em equações do tipo: $x^{2}=a^{2}+b^{2} ; \quad a x=b c ; x^{2}=a b$ ? .

Segundo Boyer (1978), após o III século antes de Cristo segue-se um longo período de declínio interrompido apenas entre 250 a 350 d.C. em que surge o maior algebrista grego Diofanto de Alexandria, que escreveu uma importante obra intitulada Arithmética. Essa obra traz enormes contribuições para o desenvolvimento da álgebra, principalmente no que se refere à simbologia. Além disso, contempla a utilização de certas técnicas de natureza algébrica, como: transformações de expressões, substituição, eliminação, etc., mesmo que implícitas. 
Desse período podemos concluir que as equações eram significativamente concebidas de maneira diferente dos babilônios e egípcios, pois os gregos não estavam procurando resolver equações que tinham sido originadas de problemas de ordem prática. A noção de equação utilizada pelos gregos contemplava um caráter geométrico e, de forma dedutiva, suas resoluções repousavam em manipulações geométricas, como percebemos, por exemplo, no método das proporções.

Outro ponto importante a se destacar é a diferença na concepção de equação, pois, enquanto para os babilônios e egípcios as equações eram concebidas como uma igualdade entre duas quantidades, isso era inconcebível para os gregos, pois as operações com segmentos e figuras geométricas não permitiam que se igualassem grandezas de dimensões diferentes.

Por outro lado, percebemos que mesmo com a mudança de concepção acerca da álgebra nesse período - de aritmética, nos babilônios e egípcios, para geométrica, nos gregos - a busca pelas soluções ainda estava relacionada à equações particulares e não a métodos gerais.

\section{Árabes e Hindus}

A matemática árabe se desenvolveu a partir de muitos problemas relacionados ao comércio, à arquitetura, à astronomia, à geografia, à ótica; tendo como característica presente, a relação entre a solução desses problemas e um trabalho teórico intenso.

Puig (1998) traz um estudo bastante detalhado sobre um dos principais nomes da época que foi al-Khwarizmi. Ele escreveu duas importantes obras sobre aritmética e álgebra, dentre as quais destacamos IIm al-Jabr Wa al Muqabalah, que pode ser entendida como "restauração por transposição de termos de um lado da equação para o outro". Foi uma das obras que mais trouxe contribuições para o estudo das equações.

Nesse livro, aparecem pela primeira vez, regras para resolver equações de $1^{\circ}$ e $2^{\circ}$ graus a coeficientes numéricos. Pode-se dizer que essas regras são semelhantes àquelas utilizadas hoje em dia para resolver as equações do 1ㅇgrau. A álgebra de al-khwarizmi, presente na obra Ilm alJabr Wa al Muqabalah, deixa-nos como herança duas expressões que tomaram significados muito fortes e presentes na resolução de equações: al-Jabr e al Muqabalah.

Para resolver alguns tipos de equações al-khwarizmi utilizava duas operações fundamentais al-jabr e al muqabalah, que significam:

- al-jabr é a operação que soma a ambos os membros da equação termos iguais;

- al muqabalah é a operação que reduz ou elimina termos iguais de ambos os membros da igualdade. 
Todas as equações tratadas por ele podiam ser reduzidas a seis tipos, em sua forma canônica:
1) $a x^{2}=b x$
4) $a x^{2}+b x=c$
2) $a x^{2}=c$
5) $a x^{2}+c=b x$
3) $b x=c$
6) $b x+c=a x^{2}$

Em Puig \& Rojano (2004) pode-se constatar ainda que nessa obra de al-Khwarizmi podese ver que a representação do que é necessário para resolver os problemas se faz mediante dois instrumentos distintos:

- Os "tipos de números que aparecem nos cálculos" - tesoros (mâl, valores em dinheiro ou tesouros), raízes (jidr) e números simples (adad mufrad, um certo número de dirhams, a moeda árabe). A conceitualização das equações escritas por al-Khwarizmi, em forma retórica na língua árabe, trata de transações comerciais, relações geométricas ou qualquer outra coisa;

- Além dessas três terminologias utilizadas, al-Khwarizmi usava o termo shay' (cosa) para designar uma quantidade desconhecida de um problema em uma equação, permitindo assim que se expresse, de forma retórica, operações aritméticas com o desconhecido.

Como visto, a cosa, por um lado, e tesoro, raiz e número simples, por outro, estão representando elementos de natureza diferentes: a cosa serve para representar quantidades desconhecidas (e para poder operar com ela) e, tesoro, raiz e números simples, representam tipos ou espécies de números. Essa distinção não se fazia, por exemplo, na álgebra babilônica.

Percebe-se na obra de al-Khwarizmi uma preocupação na busca pelas formas canônicas possíveis para se resolver qualquer tipo de equação quadrática. Embora ele não dispusesse de uma linguagem simbólica, como temos atualmente, al-Khwarizmi conseguiu elaborar um catálogo com as formas canônicas utilizando-se unicamente de linguagem natural e algumas figuras geométricas.

Em Struik (1992) levantou-se que outro matemático árabe que contribuiu para a teoria das equações foi Omar Khayyam, que encontrou uma solução geométrica para a equação cúbica do tipo $x^{3}+a x=b$ utilizando a intersecção do círculo $x^{2}+y^{2}=q x$ com a parábola $x^{2}=$ py. Ele também trabalhou com a cúbica do tipo $x^{3}=a x+b$ utilizando a intersecção da parábola $x^{2}=\sqrt{a} y$ com a hipérbole eqüilátera $x\left(\frac{b}{a}+x\right)=y^{2}$.

A matemática hindu era freqüentemente descrita como uma matemática intuitiva. Os matemáticos indianos tinham uma predileção em trabalhar com números nas operações aritméticas ou na resolução de equações, utilizando freqüentemente os métodos da 
falsa posição ou de inversão, no qual se trabalha "de trás para frente", a partir dos dados do problema.

Grandes contribuições foram dadas à Álgebra e em especial à Teoria das Equações por dois matemáticos hindus muito conhecidos na História da Matemática: Brahmagupta e Bháskara.

Segundo Bashmakova \& Smirnova (2000), Brahmagupta, matemático hindu que viveu em 628 na Índia central, encontrou soluções gerais das equações quadráticas, determinando duas raízes, inclusive sendo uma delas negativa. Pode-se observar uma influência da Matemática grega em Brahmagupta. Ele foi o primeiro a encontrar todas as soluções inteiras possíveis para a equação linear diofantina $a x+b y=c$ onde $a, b$ e c são inteiros, enquanto Diofanto, em sua época, procurava uma solução racional qualquer.

Percebe-se também uma "sincopação" da Álgebra em seus trabalhos, pois ele, assim como outros hindus, utilizava-se da justaposição para indicar a adição; um ponto sobre o subtraendo para indicar a subtração; bha para indicar a multiplicação; y $\bar{a}$ para denotar a incógnita; dentre outras.

O mais importante matemático hindu do século XII foi Bháskara, que preencheu algumas lacunas na obra de Brahmagupta, e conseguiu representar, através de sua obra, um culminar das contribuições hindus anteriores. A mais conhecida, Lilavati, é uma compilação de problemas de Brahmagupta dentre outros, que continha muitos problemas sobre progressões aritméticas e geométricas, equações lineares e quadráticas.

Bháskara, assim como seu antecessor Brahmagupta e outros hindus, aceitavam os números negativos e irracionais, e chegaram a duas importantes identidades,

$$
\sqrt{a \pm \sqrt{b}}=\sqrt{\frac{\left(a+\sqrt{a^{2}-b}\right)}{2} \pm \sqrt{\frac{\left(a-\sqrt{a^{2}-b}\right)}{2}}}
$$

as quais podem ser empregadas para encontrar a raiz quadrada de um número racional.

Utilizando-se do conhecimento deixado por outros matemáticos hindus, principalmente Brahmagupta, Bháskara unificou a solução geral das equações quadráticas pelo método de complemento de quadrados, hoje em dia conhecido por método hindu. Essa importante fórmula geral para a resolução da equação de $2^{\circ}$ grau $a x^{2}+b x+c=0, \quad x=\left(-b \pm \sqrt{b^{2}-4 a c}\right) / 2 \mathrm{a}$, é conhecida nos dias atuais como Fórmula de Bháskara.

Percebemos então que tanto árabes como hindus trabalhavam com equações originárias de problemas de ordem prática, assim como os babilônios e os egípcios já tinham feito, além de 
situações que recaiam em interpretações e manipulações geométricas, como os gregos já o faziam.

Contudo, é notório que as questões investigadas por árabes e hindus parecem dar à noção de equação, cada vez mais, um caráter algébrico. $O$ catálogo de expressões que se sabe resolver passa do específico - constituído pela acumulação de problemas resolvidos, técnicas e procedimentos de resolução particularizados - para um catálogo de todas as formas canônicas possíveis.

A álgebra babilônica não supera esse objetivo, pois, embora existissem catálogos de técnicas e problemas, esses nada têm a ver com as figuras geométricas. Os procedimentos de resolução são analíticos e reduzem as configurações a outras que se saibam resolver, ponto que também não é superado, tampouco, pela obra de Diofanto.

A noção de equação utilizada pelos árabes e hindus já apresenta uma concepção mais estrutural, no sentido de se observar as características e propriedades definidas em uma classe de equações e não mais em equações relacionadas a situações particulares.

Assim, com os objetivos presentes na álgebra dos árabes e hindus, percebe-se que a busca pelas formas canônicas caminha no sentido de que se elabore um catálogo no qual seja possível resolver todas as formas canônicas Com isso, al-Khwarizmi estabelece todas as possibilidades para o que conhecemos por trinômios de grau não superior a dois.

Desta forma, pode-se concluir aí que, antes de al-Khwarizmi sabia-se resolver problemas quadráticos com procedimentos típicos e depois dele, tornou-se possível resolver qualquer problema quadrático.

Ao mesmo tempo, podemos notar na obra de Omar Khayyam uma concepção de equação mais relacionada a um caráter geométrico, quando ele utiliza procedimentos geométricos para interpretar as equações e suas soluções como a intersecção de curvas geométricas.

\section{Os Europeus}

No Renascimento, no campo das ciências, mais especificamente na Matemática, foi publicada na Itália a mais conhecida obra de Álgebra, escrita por um frade chamado Luca Pacioli: "A Summa de arithmetica, geométrica, proportioni et proportionalita". Essa obra, que foi concluída em 1487, envolve aritmética, geometria, álgebra e contabilidade, sendo que na parte da Álgebra, ela discute a resolução usual de equações lineares e quadráticas. 
Analisando as obras de Garbi (2006) e Lintz (1999), levantou-se que, provavelmente um dos maiores e mais extraordinários feitos matemáticos ocorridos no século XVI foi a descoberta, por matemáticos italianos, da solução algébrica das equações cúbicas e quárticas. $O$ primeiro matemático que conseguiu resolver algebricamente equações cúbicas do tipo $x^{3}+m x=n$ foi o bolonhês Scipione del Ferro. Em 1515, baseando seu trabalho, provavelmente em fontes árabes, ele encontrou tal resultado.

Nicolo Fontana, mais conhecido por Tartaglia, nasceu em 1499, escreveu Nova Scientia (1537) que trata de uma aplicação da matemática à artilharia, sendo descrito no livro os novos métodos e instrumentos de balística. Foi o primeiro italiano a traduzir e a publicar Os Elementos de Euclides, em 1543, e no ano de 1546 publicou a Quesiti et inventioni diversi. Por volta de 1535, Tartaglia anunciou ter descoberto uma solução algébrica para a equação cúbica $x^{3}+p x^{2}=n$.

Outro matemático italiano que estudou as equações de 3으 grau foi Cardano, que nasceu em Pavia, no ano de 1501, e estudou medicina na Universidade de Pádua. Em 1545, em sua obra Ars Magna, ele publicou uma resolução para as equações cúbicas, mesmo sob os protestos de Tartaglia que o acusava de plágio.

Pouco depois da resolução da cúbica, encontrou-se também a resolução da equação quártica. Em 1540, o matemático italiano Zuanne de Tonini da Coi propôs um problema a Cardano que recaía numa equação quártica. Embora Cardano não tivesse conseguido resolver essa equação, seu discípulo Ferrari o fez, e Cardano publicou essa resolução também em sua obra Ars Magna.

François Viète nasceu na França em 1540 e é considerado por muitos como precursor da Álgebra simbólica. Foi o primeiro algebrista a demonstrar as vantagens no uso de letras para designar quantidades desconhecidas, ou incógnitas. Em 1591, publicou a obra In Artem Analyticam Isagoge - Introdução à Arte Analítica - provavelmente seu trabalho mais famoso. Nessa obra, Viète trata o desenvolvimento do simbolismo algébrico, introduzindo uma convenção extremamente importante para a escrita das equações na forma geral, pois, para representar uma quantidade, supostamente desconhecida ou indeterminada, usava uma vogal, e para representar uma grandeza ou números supostamente conhecidos ou dados, uma consoante.

Contudo, apesar de ter adotado essa simbologia, a Álgebra de Viète consistia fundamentalmente em palavras e abreviaturas, como: $x^{3}$, Viète representava por $x$ cubus; $x^{2}$, ele representava por $x$ quadratus; o sinal de $=$, Viète representava por aequalis; a multiplicação, por in; a divisão Viète representava por /. Outro ponto merecedor de destaque na obra de Viète é a conhecida transformação que acrescenta às equações cúbicas do tipo $x^{3}+3 a x=b$, uma nova quantidade desconhecida $y$, que se relaciona a $x$ pela equação $y^{2}+x y=a$. Com isso, a cúbica em $x$ se reduz a uma quadrática em $y$, que pode ser resolvida facilmente. 
Outro matemático que contribuiu significativamente para o desenvolvimento da história das equações foi René Descartes, nascido em 1596, na França. Segundo Puig (1998) pode-se dizer que suas maiores contribuições deram-se na continuidade do desenvolvimento da linguagem algébrica, o que possibilitou a construção de seu método para resolução de equações.

Esse método pode ser apresentado, resumidamente, dentro das seguintes fases:

- Leitura analítica do enunciado do problema e a redução a uma lista de quantidades e relações entre essas quantidades;

- Escolha de uma quantidade que será representada por uma letra (ou de várias quantidades e várias letras);

- Representação das outras quantidades mediante expressões algébricas que descrevam a relação (aritmética) entre essas quantidades e outras que tenham sido previamente representadas por uma letra ou por uma expressão algébrica;

- Estabelecimento de uma equação (ou várias, se for o caso) igualando-se as expressões obtidas anteriormente.

Descartes começa, a partir daí, a fazer uma outra análise sobre a "sua" Álgebra, pois passa a tomar as próprias equações não mais como um meio de organização de fenômenos, mas no sentido de propor um movimento de matematização vertical, que necessita de novos meios para sua organização. A partir da idéia: se $a$ é uma raiz da equação, $x-a$ divide o polinômio correspondente, Descartes explora o número de raízes das equações, o efeito que tem sobre as raízes o fato de trocar $x$ por $y-a$, etc. Embora Cardano e Viète já tivessem se debruçado sobre tais idéias, Descartes afirmou que sua Álgebra inicia-se justamente onde parou a de Viète (em sua obra De emendatione oequatotionum).

Em sua obra Geometria, Descartes retoma o método de escrever equações a partir de problemas, utilizando a idéia de supor conhecido o que é desconhecido, continuando o desenvolvimento de seu método no que diz respeito à transformação das equações. Nesse trabalho, Descartes não expõe as regras de transformações das expressões algébricas, pois as dá por conhecidas, o que ele destaca é a forma pela qual se obtém a equação canônica. A forma canônica da equação, escrita da maneira mais geral é:

$$
x^{n}=a_{n-1} x^{n-1} \pm a_{n-2} x^{n-2} \pm \ldots \pm a_{2} x^{2} \pm a_{1} x \pm a_{0}
$$

Vimos que as formas canônicas estabelecidas por ele não apresentam um polinômio igualado a zero, o que ele o faz mais tarde somente em sua obra, quando trata do que chama "sua álgebra". De forma diferente dos gregos, Descartes rompe com a vinculação geométrica dos nomes das espécies ao mostrar, logo no início de sua obra Geometria, que o produto de uma linha por uma linha pode ser representada por outra linha e não como uma superfície, 
diferentemente dos gregos, fazendo assim que as espécies "quadrados" ou "cubos" deixem de ser heterogêneas.

A combinação das letras de Viète - para representar as quantidades desconhecidas (e conhecidas) - com os números de Chuquet e Bombelli - para representar as espécies - foi necessária para que ambas as categorias estivessem representadas de maneira diferenciada e eficiente para o cálculo sintático, possibilitando assim que se fechasse um sistema de signos para a álgebra simbólica, sistema esse utilizado por Descartes e, posteriormente, por Euler.

Retomando o estudo da obra O Romance das Equações Algébricas (Garbi,1997), Leonhard Euler nasceu na Suíça em 1707 e trouxe grandes contribuições para a Álgebra, e mais especificamente para as equações. Seu trabalho com os números complexos desempenhou um papel muito importante na teoria das equações algébricas, pois, quando buscava resposta à questão de como extrair uma raiz enésima de um número complexo, Euler descobriu que qualquer número complexo não nulo (inclusive os reais) tem exatamente $\mathbf{n}$ raízes enésimas. Esse resultado aguçou os ânimos de muitos matemáticos da época, pois desde à época de Cardano, já se sabia que as equações de $3^{\circ}$ grau tinham 3 raízes e as de $4^{\circ}$ grau 4 . Com os resultados descobertos por Euler, muitos passaram a fazer conjecturas, sem conseguir provar, que as equações polinomiais de grau $n$ tinham exatamente $n$ raízes.

Na mesma obra (Garbi, 1997) discute as contribuições que Carl Friedrich Gauss, nascido em 1777 na Alemanha, trouxe para a teoria das equações. A primeira demonstração plenamente satisfatória que deu para o Teorema Fundamental da Álgebra - toda equação polinomial com coeficientes reais ou complexos e de grau $n, n>0$, tem pelo menos uma raiz complexa - demonstração está produzida em sua tese de doutoramento em Matemática. Ao demonstrar que as equações polinomiais de grau $n$ têm ao menos uma raiz complexa, Gauss demonstrou que elas têm exatamente $n$ raízes, sendo $\boldsymbol{n}$ o grau do respectivo polinômio. Utilizando-se a raiz complexa encontrada, conhecimentos de álgebra elementares conseguem-se reescrever o polinômio original por outro de grau $n-1$ e aplica-se o resultado do teorema novamente, verificando-se que o polinômio original tem exatamente $n$ raízes.

A partir da demonstração do Teorema Fundamental da Álgebra podem ser deduzidas relações muito importantes entre os coeficientes e as raízes de qualquer equação algébrica, como por exemplo, que toda equação polinomial de coeficientes reais e de grau ímpar tem pelo menos uma raiz real, pois como a equação tem exatamente $n$ raízes e $n$ é impar, sabendo-se que as raízes complexas sempre aparecem aos pares, pelo menos uma raiz é real.

Outro resultado importante para o estudo das equações algébricas, embasado no teorema fundamental da álgebra, foi o Teorema de Bolzano, matemático tcheco que viveu na mesma época que Gauss: Dados uma equação algébrica de coeficientes reais em sua forma 
canônica, $P(x)=0$, e dois números reais $a$ e $b(a<b)$, se $P(a)$ e $P(b)$ tiverem o mesmo sinal, o número de raízes reais da equação (eventualmente repetidas) será par dentro do intervalo $(a, b)$; se $P(a)$ e $P(b)$ tiverem sinais opostos, o número de raízes reais da equação (eventualmente as repetidas) será ímpar dentro do intervalo (a,b).

Niels Henrik Abel (1802-1829), ainda enquanto estudante na Noruega pensou ter encontrado a solução geral das equações quínticas, contudo, ele mesmo percebeu um erro em sua demonstração e, em 1824, publicou o artigo "Sobre a resolução de equações algébricas", no qual deu a primeira prova de que era impossível estabelecer a solução da equação quíntica por meio de radicais.

Ao mesmo tempo em que Abel buscava a solução das equações quínticas, outro grande matemático, o francês Évariste Galois (1811-1832) também o fazia. O objetivo principal das pesquisas de Galois era justamente o de determinar quando as equações polinomiais eram resolúveis por radicais.

Ainda, aos dezessete anos de idade, Galois cometeu o mesmo erro que Abel, pois imaginou ter encontrado a solução geral para as equações do $5^{\circ}$ grau. Logo em seguida publicou o artigo "Pesquisas sobre as equações algébricas de grau primo", no qual apareciam indícios daquela que seria sua maior contribuição para a Álgebra, a Teoria dos Grupos.

Galois vislumbrou os alicerces de uma forma revolucionária de se abordar as equações algébricas. Inspirado pela prova de Abel - sobre a irresolubilidade por radicais das equações quínticas -, e nos trabalhos de Lagrange - sobre as permutações das raízes de uma equação polinomial -, Galois desenvolveu a teoria dos grupos, que permite investigar a possibilidade de resolução das equações quinticas, por meio de radicais. A teoria de Galois fornece um método para determinar se raízes de uma equação algébrica podem ser expressas por radicais, contudo, a ênfase dada por esse método na teoria das equações geralmente se volta mais para a estrutura algébrica do que para o tratamento de casos específicos.

Assim, pode-se concluir que nesse período da história das equações, da mesma forma como já havia ocorrido com os árabes e hindus, principalmente com al-Khwarizmi, as equações eram vistas dentro de um sistema estrutural com propriedades e características definidas.

A noção de equação nesse período, até a resolução das cúbicas e quartícas, é considerada um objeto de investigação, pois as operações são levadas a cabo sobre elas mesmas, debruçandose na busca de soluções gerais para esses tipos de equações. Isso é uma característica que diferencia a maneira que a mesma era concebida pelos babilônios ou egípcios, por exemplo. 
Percebemos que Descartes, quando da utilização de seu método cartesiano, passou a considerar as equações não mais como um meio de organização de fenômenos, mas sim como um campo de objetos que necessitava de novos meios para sua organização.

Outro momento importante ocorreu quando da descoberta das fórmulas gerais para a resolução das equações de terceiro e quarto graus, pois a partir daí, houve uma modificação no rumo das investigações: a pergunta investigada deixou de ser qual era o algoritmo de resolução da forma canônica para: será que existe tal algoritmo e quais são as condições para sua existência.

Para a resposta dessa nova questão, as equações continuaram sendo tratadas com o mesmo caráter estrutural apresentado por seus antecessores, como em Abel e Galois, por exemplo, que o que se tornou objeto de investigação foi a estrutura do processo de resolução das equações, o que possibilitou demonstrar que não existia um algoritmo capaz de resolver, por meio de radicais, as equações de grau superior a quatro.

\section{Conclusões e Considerações Finais}

Percebemos ao longo da apresentação deste estudo epistemológico-histórico as diferentes maneiras como a noção de equação foi concebida e tratada pelos estudiosos em cada época histórica. Resumidamente, temos:

Babilônios e Egípcios: trabalhavam com equações que em sua maior parte eram originárias de problemas de ordem prática. A noção de equação tinha basicamente um caráter pragmático, que de forma intuitiva, se igualava a duas quantidades com a finalidade de encontrar o valor da quantidade desconhecida. Na maior parte das vezes, a busca pelas soluções estava relacionada à equações particulares, para resolver problemas específicos e os métodos utilizados estavam relacionados à idéias aritméticas, sem a preocupação de se encontrar soluções gerais;

Gregos: para eles as equações já eram concebidas de maneira diferente dos babilônios e egípcios, pois não estavam procurando resolver equações que tinham sido originadas de problemas de ordem prática. A noção de equação contemplava um caráter geométrico e de forma dedutiva. A resolução repousava em manipulações geométricas. Percebe-se que mesmo com a mudança de concepção acerca da álgebra nesse período - de aritmética, nos babilônios e egípcios, para geométrica, nos gregos - a busca pelas soluções ainda estava relacionada à equações particulares e não a métodos gerais;

Árabes e Hindus: trabalhavam tanto com equações originárias de problemas de ordem prática, quanto com situações que recaiam em interpretações e manipulações geométricas. A noção de equação já tinha um caráter mais algébrico, mais generalista, pois passou de um 
catálogo de expressões que se sabia resolver para um catálogo de todas as formas canônicas possíveis. Percebemos uma preocupação na busca de formas canônicas, como fez al-Khwarizmi ao estabelecer todas as possibilidades para o que conhecemos por trinômios de grau não superior a dois. Por outro lado, Khayyam já tinha uma concepção de equação mais relacionada a um caráter geométrico, interpretando as soluções das equações como a intersecção de curvas geométricas.

Europeus: equações eram vistas dentro de um sistema estrutural com propriedades e características bastante definidas. A equação é considerada em si própria, operando-se sobre ela mesma, com a finalidade de se encontrar soluções gerais. Após a descoberta das formulas gerais para a resolução das equações de terceiro e quarto graus, há uma modificação no rumo das investigações, a nova questão que norteia as investigações passa para: será que existe algoritmo para resolver equações com grau superior a quatro? Nessa nova direção, as equações continuaram sendo tratadas com o mesmo caráter estrutural, até que Galois encerra a discussão fornecendo condições de se decidir quando essas equações são solúveis por radicais.

É possível verificar, por este estudo epistemológico-histórico apresentado, que durante muitas décadas o principal objeto de investigação em Álgebra foi o estudo das equações algébricas. Contudo, percebe-se também que houve ao longo da história da Álgebra, uma mudança significativa na natureza do objeto de investigação desse campo de conhecimento matemático - o estudo das equações perde o foco de atenção dos matemáticos para o estudo das estruturas matemáticas. Com isso, podemos dizer que tivemos dois grandes momentos históricos: antes dessa mudança tínhamos o que é denominado por Álgebra Clássica ou Elementar e, depois, o que é chamado de Álgebra Moderna ou Abstrata.

A conclusão que emana das reflexões propiciadas por este estudo epistemológicohistórico, permite-me apresentar ao menos três formas diferentes de se conceber equação: uma relacionada a um caráter pragmático, outra relacionada a um caráter geométrico e uma terceira relacionada a um caráter estrutural.

Retomando aqui as discussões propostas por Duval $(1993,2003)$ enfatizo que as possibilidades e potencialidades que o trabalho com diferentes formas de conceber a noção de equação, às quais estão relacionadas diretamente com diferentes registros de representação semiótica, podem trazer para a construção do conhecimento matemático. Duval afirma em sua teoria que é necessário, mas não suficiente, que os estudantes sejam capazes de representar um mesmo objeto matemático por mais de um tipo de registro de representação semiótica.

No processo de ensino e aprendizagem da Matemática, Duval lembra:

(...) uma das características mais importantes da atividade matemática é a diversidade dos registros de representação semiótica que ela mobiliza 
obrigatoriamente. No entanto, essa diversidade raramente é levada em conta no ensino. Ora, se se quer analisar as dificuldades de aprendizagem em matemática, é preciso estudar prioritariamente a conversão das representações e não os tratamentos. Naturalmente, para poder estar em posição de observá-la, é preciso começar por distinguir bem esses dois tipos de transformação das representações, o que é raramente ou jamais feito, seja porque se estima que a conversão é somente uma forma particular de tratamento, seja porque se acredita que ela depende de uma compreensão conceitual, isto é, de uma atividade "puramente mental", quer dizer, a-semiótica. (DUVAL, 2003, p. 30)

A partir dessas três diferentes formas de se conceber a noção de equação, pode-se relacioná-las com diferentes registros de representação semiótica ${ }^{1}$, dentro do processo de ensino e aprendizagem da Matemática, a saber:

Registro na língua natural: como aparece basicamente nos Babilônios e Egípcios;

Registro geométrico: como aparece nos Gregos, por exemplo;

Registro algébrico: como começa a aparecer nos Árabes e Hindus e perpetua-se nos Europeus.

Assim, a reflexão com a qual encerro o presente trabalho levanta a importância de se trabalhar de forma articulada as diferentes maneiras de se conceber a noção de equação, trabalho este que pode contribuir para a construção de significados mais amplos para a noção de equação, nas aulas de Matemática. Um estudo mais profundo e detalhado dos multisignificados para a noção de equação no ensino de Matemática pode ser encontrado na tese de doutoramento "Equação e seus multisignificados no ensino de Matemática: contribuições de um estudo epistemológico" defendida em maio de 2007, no Programa de Estudos Pós Graduados em Educação Matemática da PUC/SP (Ribeiro, 2007).

\section{Referências}

BASHMAKOVA, I. G., SMIRNOVA, G. S. The Beginnings and Evolution of Álgebra.

Washington, D.C.: The Mathematical Association of América, 2000.

BEDNARZ, N., KIERAN, C., LEE, L. Approaches to algebra: perspectives for research and teaching. Holanda: Kluwer Academic Publishers, 1996.

\footnotetext{
${ }^{1}$ Para aprofundamento sobre a Teoria dos Registros de Representação Semiótica, aconselha-se ler as obras que constam das referências bibliográficas, tais como Duval, 1993 e Duval, 2003.
} 
BEKKEN, O. B. Equações de Ahmes até Abel. Rio de Janeiro: Universidade Santa Úrsula, GEPEM, 1994.

BOURBAKI, N. Elements de História de las Matemáticas. Madrid: Alianza Editorial, 1976.

BOYER, C. História da Matemática. 2 ed. São Paulo: Edgard Blücher, 1978.

COTRET, R. S. Problématique à propos de la mise en équation de problèmes écrits. IX Séminaire Franco-Italien de Didactique de I'Algèbre, 1999, p. IX-23 - IX-37.

DAHAN-DALMEDICO, A., PEIFFER, J. Une historie des mathématiques: routes et dédales. Paris: Éditions du Seuil, 1986.

DAMM, R. F. Registros de Representação. In MACHADO, S. D. A. et al. Educação Matemática: uma introdução. 2ª edição. São Paulo: EDUC, 2000, p. 135-153.

DUVAL, R. Registres de Représentations sémiotique et fonctionnement cognitif de la pensée. Annales de Didactique et Sciences Cognitives. ULP, IREM Strasbourg 5, 1993, p. 37-65.

Registros de Representações Semióticas e Funcionamento Cognitivo da

Compreensão em Matemática. In MACHADO, S. D. A. (org) Aprendizagem em Matemática:

Registros de representação semiótica. Campinas: Papirus, 2003, p. 11-33

EVES, H. Introdução à História da Matemática. Campinas: Unicamp, 2004.

GARBI, G. G. O Romance das Equações Algébricas. São Paulo: Makron Books, 1997.

A Rainha das Ciências: um passeio histórico pelo maravilhoso mundo da matemática. São Paulo: Livraria da Física, 2006.

KIERAN, C. The learnig and teaching of school algebra. Handbook of Research on Mathematics Teaching and Learning, 1992.

LINTZ, R. G. História da Matemática. vol I. Blumenau: Editora da FURB, 1999.

PUIG, L. Componentes de una historia del álgebra. El texto de al-Khwârizmî restaurado. In F. Hitt (Ed). Investigaciones em matemática educativa II. México, DF: Grupo Editorial Iberoamérica, 1998, p. 109-131.

PUIG, L; ROJANO T. The history of Álgebra in Mathematics Education. In The Future of the Teaching and Learnig of Álgebra. The 12th ICMI Study. STACEY, K; CHICK, H.; KENDAL, M. (Editors). Massachusetts: Kluwer Academic Publishers, 2004, p. 189-223.

RIBEIRO, A J. Analisando o desempenho de alunos do Ensino Fundamental em Álgebra, com base em dados do SARESP. São Paulo, 2001. 116 p. Dissertação (Mestrado em Educação Matemática). Pontifícia Universidade Católica de São Paulo. 
Equações e seus multisignificados no ensino de Matemática: contribuições de um estudo epistemológico. São Paulo, 2007. 141 p. Tese (Doutorado em Educação Matemática. Pontifícia Universidade Católica de São Paulo.

SMITH, D. E. History of Mathematics. vol II. Nova lorque: Dover Publications, 1958.

STRUIK, D. J. História Concisa das Matemáticas. 2 ed. Lisboa: Gradiva, 1992.

Alessandro Jacques Ribeiro. Docente e Pesquisador do Programa de Pós-Graduação em Educação Matemática da Universidade Bandeirante de São Paulo (UNIBAN). alessandro.ribeiro@uniban.br 